\title{
Article
}

\section{Neuroscience and family policy: What becomes of the parent?}

JAN MACVARISH

University of Kent, England

\section{ELLIE LEE}

University of Kent, England

PAM LOWE

\section{Aston University, England}

\begin{abstract}
This paper discusses the findings of a study tracing the incorporation of claims about infant brain development into English family policy as part of the longer term development of a 'parent training', early intervention agenda. The main focus is on the ways in which the deployment of neuroscientific discourse in family policy creates the basis for a new governmental oversight of parents. We argue that advocacy of 'early intervention', in particular that which deploys the authority of 'the neuroscience', places parents at the centre of the policy stage but simultaneously demotes and marginalises them. So we ask, what becomes of the parent when politically and culturally, the child is spoken of as infinitely and permanently neurologically vulnerable to parental influence? In particular, the policy focus on parental emotions and its impact on infant brain development indicates that this represents a biologisation of 'therapeutic' governance. [145 words]
\end{abstract}

\section{Key Words}

Early Intervention: Family policy: Neuroscience: Parenting: Therapy culture: 


\section{Neuroscience and family policy: What becomes of the parent?}

The need for parents in general, and poorer parents in particular, to be educated, trained or supported in 'parenting' has become a central tenet of English policy, stretching across education, health and welfare. Indeed, in 2011, the then Minister for Children and the Family, Sarah Teather, argued for the normalisation of parenting education and training for all parents, indicating the priority given in Government thinking to this particular policy solution (Department for Education 2011a). The rationale for this approach relies on appeals to 'evidence' which link 'parenting' directly and causally to such varied issues as poverty, educational attainment, antisocial behavior, criminality, obesity and mental health. It is claimed that since there is a causal relationship between parenting and these social problems, the 'evidence' can show us how to intervene to 'improve parenting', thus addressing these problems at an early stage or preventing them from arising at all.

Social scientists have offered various explanations for the growth of government concern about how parents raise children (Parton 2006; Gillies 2011; ANON. 2014). Of particular interest for this paper is an analysis which sees a relationship between policy calls for 'evidence-based' parenting-improvement programmes and a broader and deeper shift from an 'implicit' to an 'explicit' family policy. Scholars have identified a significant transition away from a tradition of 'reluctance' in Britain's family-related policymaking, towards the legitimation of more overt agendas which seek to address perceived social problems through measures explicitly aimed at changing parental behaviour (Clarke 2006 and 2007). It has been suggested that a very marked line of thinking emerged in Britain from the late 1990s, in which the idea that there is watertight evidence pointing to the determinant role of parental behaviour in deciding the 'life chances' of children gained considerable cross-party influence (Furedi 2001 and 2008; Gillies 2011; Goldson and Jamieson 2002; Jensen 2010). Academics have also noted that the narrowed focus on 'parenting' was concomitant with a closing down of structural explanations for poverty, inequality and arrested social mobility (for a detailed discussion of this relationship, see ANON, 2014 and Gillies, 2011).

One way of understanding the timing of this shift is to recognize that while New Labour moved family life to the centre stage of policy-making from the start of its time in office (1997), this politicization of family relationships developed simultaneously with a disavowal of concern for the 'traditional' form of 'the family'. The new politics of family were characterized by the problematising of 'parenting' rather than 'family breakdown'. By the early years of the new millennium, 'parenting' had emerged in this way as a politicised term, bound up with the idea that what parents are doing is problematic and requires 
amendment through direct government intervention, usually termed 'support' (Furedi 2001 and 2008; ANON. 2014). The 'parenting support' agenda has been expanded and developed under the umbrella concept of 'early intervention' - a policy rationale which argues that intervening pre-emptively, in social problems conceptualized as emanating from 'dysfunctional' individuals, families or communities, reduces the later social and economic costs of such problems. Taking root in New Labour's 'social exclusion' agenda, this approach has been enthusiastically advocated by the Conservative-Liberal Democratic coalition government since its election in 2010.

The construction of 'parenting' as a policy problem has, from the outset, laid claim to the authority of a new 'evidence base' which, it is suggested, can now tell us definitively what constitutes 'good parenting'. Evidence-based parenting policy draws on a range of research approaches including epidemiological analyses; large-scale, long-term population studies tracking social inequality and differential educational outcomes; laboratory-based animal behaviour research; psychological theories of child development and evaluations of existing international parenting intervention programmes. One particular strand of claimsmaking is built around the argument that evidence from research in neuroscience provides a solid basis on which some parental behaviours can be recommended as nurturing of, and others proscribed as deleterious to, the developing child, their future life chances and to the wider social good (we will refer to this as 'neuroparenting'). However, from the late 1990s, academics from various disciplines have been raising concerns about the validity of such brain-based claims-making and the consequences of their adoption by policy-makers, first in the US but subsequently further afield: New Zealand (Wilson 2002); Canada (Wall 2004 and 2010); mainland Europe (Ramaekers and Suissa 2012) and the UK (Furedi 2008; Wastell and White 2012; ANON. 2014).

On the scientific level, it has been argued that some of the studies, claimed by neuroparenting advocates to contain novel breakthroughs with ramifications for policy, were in fact rather old, or were based either on animal studies or on studies of children with exceptional early life experiences, such as Rutter and the ERA's studies of the effects of extreme early privation on institutionalised Romanian orphans (1998). Such evidence was therefore challenged as possessing limited application to normal human development (Kagan 1998; Bruer 1999a and b; 1998a and b; 1997). Cultural theorists have proposed that the conceptualisation of the child's brain as overwhelmingly vulnerable to parental influence in the early years serves as a metaphor for the parent-child relationship which resonates with particular contemporary anxieties (Hays 1998; Nadesan 2002; Furedi 2008; Thornton 2011). When considered as part of a broader 'parenting culture' (ANON. 2014), brain-claiming can be said to further intensify the demands on parents, 
whose every action is said to have measurable and lifelong consequences for the child's emotional and cognitive wellbeing (Hays 1998; Furedi 2008; Wall 2004 and 2010; ANON. 2014). Most recently, British scholars have begun to formulate a critique of the consequences of this neurobiologised way of understanding family life for the rights of families relative to the State, most noticeably, its tendency to create a 'now-or-never imperative' to 'rescue' children from their families in the name of preventing irreversible damage to the developing brain caused by dysfunctional parenting (Wastell and White 2012; Gillies 2013; Featherstone, Morris and White 2013; ANON. 2014). Such policy thinking affects poorer families hardest when financially poor parenting becomes inextricably linked with developmentally poor parenting.

In this paper, we seek to contribute to the sociological and social policy critique by exploring how advocacy of 'early intervention', in particular that which deploys the authority of 'the neuroscience', places parents at the centre of the policy stage but simultaneously demotes and marginalises them. While we are informed by the critique which questions the scientific validity of such claiming, we wish to develop another argument as to why neuro-claims-making should be contested. The main focus here is not, therefore, on the scientific credibility of the claims, but on the ways in which the deployment of neuroscientific discourse in family policy creates the basis for a new governmental oversight of parents. Elsewhere, we explore the significance of neuropolicy for constructions of the infant (ANON. forthcoming), but here we are concerned with the construction of the parent. So we ask, what becomes of the parent when politically and culturally, the child is spoken of as infinitely and permanently, neurologically vulnerable to parental influence? We will proceed by reviewing the relevant literature and outlining the research on which our argument is based, before describing the research findings and drawing out their significance for our understanding of the contemporary policy conceptualisation of family life.

\section{Explicit family policy, neuroscientific claims-making and the opening up of the emotional world}

To understand the significance of a neurobiologised construction of parent and child in English family policy, it is important to consider it as a continuation of trends in the policy field over a longer period of time. First, our analysis of policy documents from 1997 to the present day suggests that policy concern with a 'parenting deficit' predates the adoption of brain-based claims-making by policy-makers. Second, the argument for early intervention relies on a presumption that all intimate family relationships are now a legitimate object for policy attention, where previously there was a reluctance to interfere in most families or to problematise the family per se. 
Attempts in the 1980s and 1990s to politicise 'the family' or rather, its perceived decline, in moral terms had proved difficult; for example, the call for a return to 'family values' by successive Conservative governments was seen to backfire in a war of scandal between the media and politicians (Duncan 2007). By 1997, a new approach to family policy emerged, first formally articulated in the New Labour government's report Supporting Families, published by the Home Office in 1998. The report has been identified by a number of scholars as a key turning point in English family policy where governmental concern for private life was reconceptualised from a moral concern for the outer form of 'the family' and the problematisation of people who defied that form (single mothers or same sex parents for example), to a concern with the inner qualities of the parent-child relationship (Furedi 2008; Gillies 2011; ANON. 2014). This new approach sought to address social problems through changing or managing the emotions of individuals, because it is believed, this intimate realm is the site of origin for all social phenomenon.

The tendency to interpret social phenomenon as derivations of emotional states and to enact strategies for governance which seek to engage and shape the intimate, emotional existence of individuals has been conceptualised by scholars such as Furedi (2004) and Illouz (2007) as a 'therapeutic' or 'emotional' culture. A key characteristic of a therapeutic or emotional culture, is 'a narrative of self and identity which anchors the self in childhood and in one's primary family relationships' (Illouz 2007 p.24). As Kagan (1998) and Illouz (2007) argue, the idea that the formation of the personality during childhood is determinate of the personality and fortunes of the future adult has long cultural roots, rendering infancy a risky time of potentially permanent damage. The focus on the childhood years can be understood as the result of a search for an origin to social phenomenon in the private domain of interpersonal relationships, and to a certain extent, the 'natural' processes of infant development and basic human interactions of care. The relationship between parent and child is thus constructed as both naturally foundational to society but also too risky and important to be left to the unseen vagaries of the private realm.

Concern for the welfare of the child and the increasing conceptualization of the (vulnerable) child's interests as separate to, or in conflict with, those of its parents, grew in the 1970s and 1980s, with the child, according to Wyness, becoming a 'centripetal force within a reconfigured public realm' $(2012$, p.6). But making the child an object of political and social action requires, as Rose describes, the 'petty details of the domestic, conjugal and sexual lives of their parents' to be brought in to public view, scrutinized and evaluated (Rose 1999, p.123). In other words, when family life is presumed to be the origin of all social 
phenomena, political concern for the child inevitably problematises the behaviour of parents. The call for 'early' intervention is a call for the State to act pre-emptively to protect the child from their parents, in the belief that it is possible to identify and predict particularly 'risky' situations, and that doing so can prevent future problems for the individual and for society (Parton 2006; Wyness 2012; Lawless, Coveney and MacDougall, 2013).

As we introduced earlier, the period from the late 1990s has been understood by a number of scholars to represent a shift from an 'implicit' to an 'explicit' family policy (Wasoff and Dey 2000; Clarke 2006; Lewis 2011) characterized by far more direct pronouncements from politicians on how children ought to be raised and an increasing willingness to blame parenting for social ills. This approach has been given concrete form through the development of a discrete area of policy 'offering services to parents around the way that they parent' (Daly 2013, p.163), the establishment of new institutions of 'parenting support' and parenting 'expertise' and the funding and training of a 'parenting workforce' (Gillies 2011). Daly argues that, since 1997, 'England could be said to be in some ways an archetype in that it has put in place the most elaborate architecture anywhere for parenting support' (Daly 2013, p.164). Lewis describes how this policy purview has been extended beyond those parents whose children's behaviour had already brought them to the attention of social services, to all parents, who are now encouraged to access universally provided parenting support services in advance of any problems being evident to themselves or others (Lewis 2011, p.107).

\section{Neuroscience versus neuroscientism}

As noted earlier, the invocation of 'brain science' has become a growing feature of parenting policy and parenting culture. Thornton (2011) has labeled the vigorous advocacy of brain-based early intervention the 'first three years movement': an alliance of child welfare advocates and politicians which claims that social problems such as inequality, poverty, violence, lack of educational achievement, mental and physical ill-health, can be ameliorated or prevented if policy can secure functional infant brain development. Brain-based early intervention therefore sets itself the task of changing parental behaviour to be more attentive to the developmental 'needs' of the infant brain in the early years of life. The first three years movement first emerged in the US in the 1990s and has gained ground since in most AngloAmerican, and an increasing number of other national and supranational, policy contexts. This is despite the scientific validity of its brain claims being questioned from the start. 
Critics have challenged the movement's interpretation of scientific data and its tendency towards rigid infant determinism: arguing that contra the movement's insistence that the early years are 'critical' in a now-or-never sense, in fact, the human brain is defined by its plasticity rather than its rigidity and that human development is marked by resilience rather than vulnerability (Bruer 1997, 1998a, 1998b, 1999a and 1999b; Kagan 1998; Thompson and Nelson 2001; Rutter 2002; Belsky and de Haan 2011). To a certain extent, the movement accepts that the brain is 'plastic' rather than fixed, but this concession has not led to a rejection of infant determinism, but rather it has strengthened the argument that the brain is incredibly vulnerable to parental influence, precisely because of its plasticity. We will explore this further below. As the first three years movement grew and internationalized, it also provoked a growing critical response among scholars who have sought to contextualise its appeal within a broader parenting culture which has intensified demands on parents in general and the scrutiny of mothers in particular (Hays 1998; Wilson 2002; Wall 2004 and 2010; Lupton 2011; Lawless, Coveney and MacDougall 2013; ANON. 2014). We will engage with this literature towards the end of the paper.

Despite the growing body of scholarship questioning the scientific integrity of brain claims and expressing concern about the implications of such a policy framework for the status of parents and the wellbeing of children (Wastell and White 2012; Edwards, Gillies and Horsley 2013; Featherstone, Morris and White 2013; ANON. 2014), the brain-based early intervention agenda has colonised the policy frame with almost no acknowledgement that it might be controversial. We now turn to our own research to explore the development of the first three years movement in the British context.

\section{The study}

This paper is informed by the findings of a study tracing the adoption of neuroscientific claims-making by English family policy. The study, (DETAILS REMOVED FOR ANONYMITY) involved an analysis of English policy documents which have shaped the formation of parenting policy across a number of domains (social exclusion, health, maternity services, early years, crime and justice). Not discussed here, but informing our interpretation of contemporary British developments, were 1) a review of historical literature on past movements seeking to 'save' children from malign parental influence and 2) a review of the literature critiquing the 'first three years movement' in the Anglo-American policy context. In particular, the latter allowed us to draw a useful distinction between neuroscience and 'neuroscientism', that is, between the legitimate findings emerging from this new area of science and the fetishisation of a neuroscientific vocabulary as a source of authority to underpin policy claims-making. 
A central feature of the project was to trace how concepts and language taken from neuroscience are deployed within policy to explain the significance of parent-child relationships as the origin of social problems, but also to understand these in the longer and broader context of policy thinking about the family. To this end, an initial group of policy documents was identified to reflect the post-1997 development of a 'parenting' agenda and judged likely to contain early and subsequent articulations of brain-claiming. Follow-up of references in the initial sample, investigation of possible related areas of policy such as health or maternity services, and team discussion of an initial set of emerging themes, enabled the gaps to be gradually filled in a policy document timeline and a framework for content analysis was established using NVIVO. Forty one documents eventually constituted this purposive sample, dating from 1997 to 2013. The diffuse character of policy relating to family life meant that documents were identified in various policy domains: health, welfare, education and social exclusion. The common variable was that they were judged by the research team to contain proposals concerned to address the 'parenting deficit'. The sample was subjected to thematic analysis, facilitated by NVIVO, which involved close reading, coding and the mapping of key terms and ideas. We now turn to a discussion of our findings.

\section{Findings}

Documentary analysis allowed us to identify three key themes: a) The shift from moral to therapeutic arguments for turning the policy spotlight on family life; b) the way in which baby's brains are positioned relative to the parent and c) the observation that it is not cognitive intelligence that is at issue but the claimed emotional underpinning for it. These themes will now be discussed in turn.

\section{a) From moralizing 'the family' to politicizing parental nurture}

The first direct reference to the brain found in the sample of policy documents reviewed was in the 2003 'Birth to Three Matters' literature review, published by the Department for Education and Skills. However, our analysis shows that concern with the quality of parental nurture was well-established prior to the emergence of brain claims, suggesting that any understanding of brain-claiming needs to be situated within the larger context of changing conceptualizations of family life as a problem in need of policy action.

In the earliest item in our sample, New Labour's Supporting Families, published by the Home Office in 1998, we found an explicit attempt to distance the new family policy from 'old' attempts to preserve the 'traditional' family, with the argument that: 
Government could not turn the clock back even if it wanted to do so. There never was a golden age of the family. Family life has continually changed - and changed for good reasons as well as bad. (Home Office 1998, p.2)

A later report similarly distanced the new family policy from a concern about family form:

This is not a debate on the shape of families and we will not try to incentivise or engineer particular family structures - this is not the job of government. (Cabinet Office 2007, p. 1)

In a report from the last days of New Labour, marriage is acknowledged as important, but is not accorded any moral or political privilege:

Marriage is an important and well-established institution that plays a fundamental role in family life in our society. However, marriage is a personal and private decision for responsible adults, with which politicians should not interfere...families come in all shapes and sizes these days and the evidence is clear that stable and loving relationships between adults in the home - parents, grandparents and other caring adults - and with their children are vital for their progress and wellbeing. (Department for Children, Skills and Families, 2010 p. 1)

We can see here a relative withdrawal from a moral component to family policy, in which the sanctity, benefits or even the historical truth of a particular family form (married, stable) are all disputed. This seems at first to contradict the overall content of the reports, which makes the case for the legitimacy of governmental concern to support 'families', 'think family' or 'support all'. The last quote indicates how this disavowal of 'old' concern for the external form of the family is bound up with an embracing of a new approach which relies on 'evidence-based' rather than moral claims for government interest in family life, where concern for the quality of relationships within 'families' replaces any interest in the structure that 'the family' assumes.

\section{b) The amazing infant brain (nurtured by inadequate parents)}

As well as being conceived of as foundational to society, family relationships are also talked of as being under 'considerable stress' (Foreword to Supporting Families by Jack Straw 1998) and the source of this 
stress is not just from relationship breakdown or lone parenting. In the 2007 report, Parenting Matters, the pressures on contemporary families are described as multiple: parents caring for elderly grandparents; mothers and fathers both working; financial pressures. A later report adds to these, rapid social and technological changes, which have 'brought families unprecedented opportunities and freedom of choice, as well as challenges in terms of responsibility and restraint' (DCSF 2010, p.1). 'The family' is not therefore described as a strong foundational unit of society, a building block, but rather, 'family life' is understood to contain vulnerable relationships, meaning that there "has never been a more important time for the Government to support families and family relationships.' (DCSF 2010, p.1).

It is useful to consider Vansieleghem's suggestion that the 'notion that we are living in a complex and permanently changing society' has a disorienting effect, and the claim of rapid social change breaks the 'possibility of historical continuity in family practices', this in turn legitimizes 'greater recourse to expertise and the expansion of measures to manage the inner life of families' $(2010, p .341)$. This theme of disorientating rapid change and the subsequent need for support exists at two levels in the documents: it is evident in descriptions of the social - economic trends and changes in family structure - but also in constructions of the individual. The most repeated claim about the infant brain is that it is distinguished from the adult brain by its capacity for extremely rapid 'growth':

Children's brains develop faster in the first two years than at any other stage and they learn more quickly. (DCSF 2007, p.10)

At birth, babies have around a quarter of the brain neurons of an adult. By the age of 3 , the young child has around twice the number of neurons of an adult - making the early years critical for the development of the brain, language, social, emotional and motor skills. (Department of Health 2010, p.18)

The child is thus estranged from adults by its distinct biological character and its complex developmental needs. This in turn leads to the argument that expert-led, neuroscientifically-informed parenting support is necessary to train the parent in the correct way to nurture the child while its brain grows at an extraordinary rate. The scientific vocabulary, here of 'neurons', but elsewhere of 'synapses', 'cognitive capacities', 'cortisol' or 'auditory maps', suggests the relationship of care between babies and parents must be mediated through the scientific and medical interpretation of experts. 
The idea of a 'critical period', typically 0-3 years, when certain 'inputs' must occur to enable normal brain development is also a key brain claim. But this is increasingly extended back before year zero, into gestation, where the vulnerable fetus is equated seamlessly with the born infant.

What happens in pregnancy and the first few years gives children a lasting legacy because they are growing rapidly and particularly susceptible to physical, environmental and psychological harm. (Department for Education and Department of Health 2011, p.51)

Early interactions directly affect the way the brain is wired, and early relationships set the 'thermostat' for later control of the stress response. This all underlines the significance of pregnancy and the first years of life, and the need for mothers and fathers to be supported during this time. (Department of Health 2008, p.9)

In its association with the fetus, traditionally understood as a mysterious, unknowable, invisible, notquite-human being, the born child is rendered even more mystifying and alien to its parents, thereby necessitating expert, scientific knowledge and even equipment such as the scanner, to identify its needs.

\section{c) Parents as 'environmental' influences}

The rapid growth of the brain during the early months and years is said to be dependent on the infant's 'environment' and this period of brain development is posed as 'critical' for the formation of the future child and adult.

A child's brain develops rapidly in the first two years of life, and is influenced by the emotional and physical environment as well as by genetic factors. (Department of Health 2008, p.11)

In the rest of the sample, it is common for 'the environment' to be given more significance than genetics, so while it is argued that the brain is essentially 'fixed' by early childhood, the 'critical window' of 'brain plasticity' when it is most receptive to 'environmental influences' is conceptually extremely important, for it this which re-frames the parental role. Contemporary brain-claiming tends to counterpose itself to the biologised infant determinism associated with genetic understandings of child to adult development, but as we noted earlier, this embracing of 'plasticity' reinvents infant determinism in a different form: parental determinism. This strong determinism is evident in the following quote from a report providing policy 
recommendations to the Conservative Party:

The emotional brain is largely created in the first 18 months of life and its auditory map is formed even earlier, by 12 months. Furthermore, it has also been shown, alarmingly, that a child's education developmental score at 22 months can accurately predict educational outcomes at the age of 26. In short, we are now able to predict the long term wellbeing of children on the basis of their environment in the first few years of their lives. (Social Justice Policy Group 2007, p.8)

In the 'neuroparenting' outlook, parents are talked of in flattering terms as 'sculptors' and 'architects' of the physical infant brain. But this determining role is double-edged, for their overwhelming influence can work for good or for ill, as has been said elsewhere, they are 'foolish gods', cast as simultaneously allpowerful and incompetent (Furedi 2008). Whilst naturally connected to the child through their great capacity to shape the child's brain and future, in other respects, parental estrangement from the child is reinforced by the relativisation of parents as just one of a number of 'environmental' factors impacting on infant brain development.

'The environment' is talked of in three notable ways: as the 'home learning environment', as 'the womb' and as 'relationships'. When described as the 'home learning environment', the family home is recast as of great public significance, because of its unique role in shaping future citizens:

The research we draw on for this pamphlet indicates that what happens inside the family, when a child is very young indeed, strongly determines how they will react to people outside the home, how ready they will be to learn and ultimately what kind of a citizen they will become. (Centre for Social Justice 2009, p.15)

The conceptualization of family members as 'environment' is most strongly biologised when it is applied to gestation, when the mother's body is, quite literally, the entire 'environment' in which the child's body and brain is forming. The uterine environment is not only conceptualized as risky because mothers can pass on physical toxins (such as drugs and alcohol) to their child, but because the mother-to-be's emotional state (often medicalised as 'mental health') is increasingly believed to be transmitted to the child.

It [the CHPP] should also incorporate the information that we have about the adverse effect that 
maternal anxiety and depression in pregnancy can have on child development (Department of Health 2008, p.9)

The propensity to experience some major mental illnesses can be inherited genetically. However the effects of poor parental mental health are also transmitted environmentally through processes during pregnancy and through family relationships. (Cabinet Office 2007, p.20)

The third way in which parents are constructed as an environmental influence is in the claim that the 'emotional environment' created by the parent directly impacts on infant brain development. This is increasingly articulated in terms of a biologised version of attachment theory, with a particular focus on maternal depression.

Maternal depression impedes brain development. Infants of severely depressed mothers show reduced left lobe activity (associated with being happy, joyful or interested) and increased right lobe activity (associated with negative feelings). (Centre for Social Justice 2008, p.65)

However, it is not just postnatal depression that is described as an inhibitor of brain development but the more nebulous parental states of 'stress' and 'anxiety' which are associated with a failure to secure attachment and can apply to both mother and father.

The development of a baby's brain is affected by the attachment to their parents and analysis of neglected children's brains has shown that their brain growth is significantly reduced. Where babies are often left to cry, their cortisol levels are increased and this can lead to a permanent increase in stress hormones later in life, which can impact on mental health. Supporting parents during this difficult transition period is crucial to improving outcomes for young children. (Field 2010, p.41)

The parent is thus held responsible for their child's future ability to function both cognitively and emotionally but also depicted in relativised, biologised terms as just another environmental factor.

\section{d) Biologised therapeutics: From IQ to Emotional Intelligence}

It was evident in the documents analysed that emotional development is of far greater concern than 
cognitive development, or rather, emotional development is said to underpin cognitive development. For example, this report aimed at tackling poverty targets the emotional development of children as the basis for overcoming inequalities:

The child who is nurtured and loved will develop the neural networks which mediate empathy, compassion and the capacity to form healthy relationships (Cabinet Office 2006, p.47)

Thornton (2011) makes the important observation that after an initial focus on nurturing IQ and intelligence in the infant brain, the first three years movement in the US absorbed a reaction against this instrumentalised view of parental care. Thenceforth, emotional development was prioritised by the movement as the logical and biological underpinning of cognitive development. In this way of thinking, neuroparenting is not primarily concerned with raising smarter babies but with raising 'emotionally intelligent' babies. As Illouz discusses, we have moved from a concern with the measurement and improvement of IQ to a prioritization of 'emotional intelligence' (Illouz, 2007). The following quotes demonstrate the ultimately cyclical therapeutic logic of locating social phenomenon in the emotional development of the infant, via, the brain.

1. Material poverty causes a detrimental maternal state, which creates an emotionally poor environment for infant:

Several studies in the US have observed families living in conditions of severe disadvantage, and have found consistent associations between the occurrence of postnatal depression and marked impairments in maternal responsiveness to the infant... (Sutton et al. 2004, p.28)

2. The child raised in an emotionally impoverished environment will be less able to function in school and in wider society. Their 'damaged' emotional state will lead to deficiencies of intelligence and antisocial behavior and, presumably, an inability to be effective parents themselves:

Repeated interactions of this kind contribute to the development of longer-term difficulties in the baby's behaviour which themselves place the child at risk of anti-social behaviour. These difficulties include low scores on ' $Q Q$ ' measures of intelligence (especially in boys), impairments in the baby's capacity to control his/her emotions and behaviour, and inability to sustain attention. (Sutton et al. 2004, p.29) 
To 'break the cycle' of the continued creation of dysfunctional individuals, all parents therefore require instruction at the earliest possible stage to attune them to their baby's neurological needs through the adoption of a neuroparenting style:

Evidence on neurological development shows how babies build connections in their brain which enable the development of speech and language, self-confidence and good relationships with other children and adults...It is imperative that children's healthy development in their first years of life is supported...Parents are informed about the importance of talking to their child and following the child's lead in their physical play whilst developing the parents' understanding of brain development. (Department for Education 2011b, p.21)

The analysis of policy discourse suggests that the neurobiologising of parental influence constructs the parent as both the supreme influence on their child but also as an inherently risky one. It is noticeable in many of the quotations above that brain-claims have a tendency to normalise as developmentally critical, 'support' for parents during the early years. The bringing of parenting to the centre of the policy stage can therefore be understood as a demotion of previous conceptions of the parent as essentially competent until proven otherwise. The scientific-sounding character of brain claims necessarily construct the baby as requiring expert medical interpretation and the parent, therefore as in need of professional guidance to absorb to incorporate this expert-delivered knowledge into their care for their child. Parenting professionals are therefore positioned as interpreters of new 'truths', working 'in partnership' with parents to access the insights of neuroscience.

\section{Discussion: Nurturing nature in a therapeutic culture}

A large number of scholars have challenged the tendency to blame parents for the ills of society and to demand that they educate themselves to improve their children's life chances as a highly individualized, atomizing view of the task of rearing children (Hays 1998; Furedi 2001 and 2008; ANON. 2014). Brainbased arguments for early intervention have been accused of providing a way of justifying cuts in welfare spending and of 'responsibilising' the raising of children solely to individual parents, particularly mothers (Gillies 2013). Similarly, Wall places neuroparenting within an understanding of neoliberalism's emphasis on 'the ability of individuals to adapt to change, to engage in self-enhancing behaviour, and to manage 
the risk they pose to themselves and thus reduce their potential burden on society' (Wall 2004 p.46). Thornton also understands neuroparenting culture as driven by a neoliberal imperative to 'reproduce entrepreneurial forms of self-governance by producing babies emotionally primed to navigate an economic system that prioritizes flexible, mobile, and adaptable workers' (Thornton 2011 p.400).

However, as we can see from the above analysis, far from facilitating a withdrawal of the State from family life or valuing parental autonomy, brain claiming is actually deployed to argue for novel State interventions to evaluate and transform the intimate interactions between parents and children. As Nadesan suggests, neuroparenting 'legitimizes more formal surveillance of, and intervention in, infant development, particularly the development of economically disadvantaged children' (Nadesan 2002 p.424). Such measures directly undermine the autonomy and authority of the parent and make it impossible for them to exercise real parental responsibility as they see fit.

The reconceptualisation of 'child-rearing' from a complex intergenerational responsibility undertaken by families and wider adult society, to a narrow, technical task, concentrated on the individual parent (Ramaekers and Suissa 2012; Smeyers 2008 and 2010) is particularly evident in the brain-based construction of the parent and child. The individualization identified by critics of neoliberalism should therefore be understood as one that is currently severely circumscribed, with its own requirements of emotional conformity, as Furedi outlines,

... a closer inspection of therapeutic culture indicates that its account of the self is far from an optimistic one. The image of the self-actualising individual gaining enlightenment through selfreflection and the exercise of autonomous choice is, in practice, contradicted by the fundamental premise of therapeutic culture, which is that the individual self is defined by its vulnerability. (Furedi 2004, p.107)

Although not writing about neuroscience, Illouz astutely observes of the therapeutic culture that the institutionalization of expert-driven concern for the emotions requires the 'capacity to display an emotional style defined and promoted by psychologists' (IIlouz 2007, p.63). And so, the apparent tendency to privatize social phenomenon should be viewed in conjunction with a recognition that new forms of intimate governance mean that the private world can no longer exist in the way it once did. As Illouz says, the therapeutic narrative, 
...makes one responsible for one's psychic well-being, yet does that by removing any notion of moral fault. Thus, it enables one to mobilize the cultural schemes and values of moral individualism, of change and self-improvement. Yet, by transposing these to childhood and to deficient families, one is exonerated from the weight of being at fault for living an unsatisfactory life. (Illouz 2007, p.55)

As Thornton highlights, today's neuroscientific-based theories see parent-child attachment as a much less natural or reliable occurrence than did the earlier proponents. Not only that, according to Thornton, bonding is 'a technical problem that must be achieved through constant work on the self, primarily through actions directed inward; towards feelings, attitudes, and desires' (Thornton 2011, p.409). This is not an argument for social advancement through the optimizing of parental care and enlightened child development, but rather the expression of an anxiety about social order - represented by the prospect of large populations of unempathic, emotionally stunted individuals - to be resolved through the securing of social bonds, conceptualized as deriving from a neurobiological foundation. Today's neurobiologisation of parental love is premised on the prior belief that there is a widespread deficit in the quality of parental care. There is little faith today in either nature OR nurture therefore.

In his influential essay The Allure of Infant Determinism (1998) demonstrating the long-standing appeal of deterministic ideas about the early years of life, the child psychologist Jerome Kagan criticised the reductionism of brain claiming. He argued that the political appeal of brain claims resides in their ability to avoid moralising parental behaviour while simultaneously focusing attention upon it. This resonates with our observation that the origins of English parenting policy coincide with a final abandonment of traditional moral arguments about family form, marriage, divorce or single parenthood and re-pose the 'problem of the family' as one which could be resolved by the evaluation of the 'internal quality of the relationships between the individuals within the family' (Gillies 2011, para 9.1). According to Kagan, brain claims divert attention from the absence of consensus about what is right and wrong in family life, or about the legitimate role of the State in raising children and turn it towards parenting 'education' as the solution to social problems.

\section{Conclusion}

Our study indicates that brain claims reinforce pre-existing ideas of early infancy being determinate of 
future life chances but also confirm the construction of the parent as the key mechanism through which this determinism is leveraged on the individual child, for good and for bad. The construction of babies' brains as extremely susceptible to parental influence can be seen as a biologised condensation of preexisting ideas about 'toxic' family relationships (Furedi 2001 and 2008; ANON. 2014). Previous social movements which biologised notions of social progress argued unapologetically for intervening in childhood to strengthen the national 'race'. In the current period, biological authority is invoked in a different way: the concern is more with the capacity of those who 'nurture' to ensure the proper development of 'nature'. The apparent naturalization of the child's needs is not paralleled in a naturalization of a parent's ability to meet them or even to recognize what they might be: for babies are now constructed as truly knowable only through scientific interpretation. For example, despite the apparently overwhelming import of the mother-child relationship, there is no confidence here in maternal instinct. Nature is therefore not inherently functional, but must be nurtured through the encouragement of particular practices and the guidance of 'neuroscientifically-informed' expertise. In constructing the child as knowable only through a scientised framework of neurological development, brain claiming inevitably demotes the parent. Parents are no longer equipped to spontaneously understand and guide their child's social and physical development, but even more significantly, they are emotionally illequipped to love their child in a way judged to be conducive to the child's successful development.

As 'partners' in their child's development, parents are consigned to a position nominally equal with paid professionals who have no intimate knowledge of the child and do not love the child. However, this 'partnership' is not, in fact, equal because the professional has a superior claim to expertise, having the task of training the parent. Not only that, state-employed professionals have the responsibility and power to monitor, evaluate and act upon parental 'skills and competencies'. This instrumental, biologised way of thinking about family life expands and intensifies the obligations of parents to new levels while at the same inherently de-authorising the parent as a 'mother' or a 'father', with a unique relationship to the child.

We therefore conclude that the uncritical embracing of early years determinism has authoritarian consequences for the relationship between all families and the State because it fundamentally reconceptualises all parents in a demoted position relative to 'expertise' and State agencies. This policy approach particularly stacks the odds against poorer parents. In rewriting social class and economic position as reproduced solely through parenting, a justification is created for the targetting of families 
deemed incapable of adequately developing their children's brains in the name of rescuing the child but also progressing society (or at least saving society from future expenditure). Policies informed by the 'first three years movement' also risk the child's well-being by hastening their permanent removal from birth families and undermining the possibility of spontaneous relationships of love and care.

\section{Endnotes}

[1] DETAILS OF STUDY REMOVED FOR ANONYMITY

\section{References [TWO ITEMS REMOVED FOR ANONYMITY]}

Belsky, J. and de Haan, M. (2011) 'Annual Research Review: Parenting and children's brain development: the end of the beginning', The Journal of Child Psychology and Psychiatry 52(4) 409-428.

Bruer, J.T. (1999a) The myth of the first three years, a new understanding of early brain development and lifelong learning, New York: The Free Press.

Bruer J.T. (1999b) 'In search of brain-based education', Phi-Delta Kappan, 80(9): 649-57.

Bruer, J. T. (1997) 'Education and the brain: A bridge too far', Educational Researcher, 26: 4-16.

Bruer J.T. (1998a) ‘Brain science, brain fiction', Educational Leadership, 56(3) 14-18.

Bruer J.T. (1998b) 'Time for critical thinking', Public Health Reports, 113(5) 389-97.

Cabinet Office (2006) 'Reaching Out: An action plan on social exclusion', London: Cabinet Office.

Cabinet Office (2007) 'Reaching Out, Think Family', Social Exclusion Taskforce, London: Cabinet Office.

Centre for Social Justice (2008) 'Early Intervention: Good parents, better kids, great citizens' ( $1^{\text {st }}$ edition), London: Centre for Social Justice.

Centre for Social Justice (2009) 'Early Intervention: Good parents, better kids, great citizens' ( $2^{\text {nd }}$ edition), London: Centre for Social Justice.

Clarke, K. (2006) 'Childhood, parenting and early intervention: A critical examination of the Sure Start national programme', Critical Social Policy, 26: 699-721.

Clarke, K. (2007) 'New Labour: family policy and gender', in C. Annesley and F. Gains (eds) Women and New Labour, Polity Press.

Daly, M. (2013) 'Parenting support policies in Europe', Relationships and Society, 2(2), 159-174.

Department for Children, Schools and Families (2007) 'Children's Plan 0-7 expert group report', 
Nottingham: DCSF.

Department for Children, Schools and Families (2010) 'Support for All: the Families and Relationships Green Paper', Nottingham: DCSF.

Department for Education (2011)a 'Free parenting classes to be offered to over 50,000 mothers and fathers', 16 October, [accessed 1/12/12]

https://www.gov.uk/government/news/free-parenting-classes-to-be-offered-to-over-50000-mothersand-fathers

Department for Education (2011)b 'The Early Years: Foundations for life, health and learning, an independent report on the Early Years Foundation Stage to HM Government', London: Department for Education.

Department for Education and Department of Health (2011) 'Supporting Families in the Foundation Years', London: Department for Education.

Department for Education and Skills (2003) 'Birth to Three Matters: A review of the literature compiled to inform the framework to support children in their earliest years', Nottingham: DfES.

Department of Health (2008) 'The Child Health Promotion Programme: Pregnancy and the first five years of life', London: Department of Health.

Department of Health (2010) 'White Paper: Healthy Lives, Healthy People: Our strategy for public health in England', London: Department of Health.

Department of Health (2011) 'Preparation for birth and beyond: A resource pack', London: Department of Health.

Duncan, S. (2007) 'What's the problem with teenage parents? And what's the problem with policy?', Critical Social Policy, 27(3), 307-334.

Edwards, R., Gillies, V. and Horsley, N. (2013) 'Policy Briefing: The biologisation of poverty. Policy and practice in early years intervention', http://www.discoversociety.org/2014/01/06/policy-briefing-the-biologisation-of-poverty-policy-andpractice-in-early-years-intervention/

Featherstone, B., Morris, K. and White, S. (2013) 'A marriage made in hell: early intervention meets child protection', British Journal of Social Work, March 1-15.

Field, F. (2010) 'The Foundation Years: Preventing poor children becoming poor adults: An independent report on poverty and life chances', Independent report for the Prime Minister, London: Cabinet Office.

Furedi, F. (2004) Therapy Culture: Cultivating vulnerability in an uncertain age, London: Routledge. Furedi, F. (2001) Paranoid parenting: Abandon your anxieties and be a good parent, London: Allen Lane. Furedi, F. (2008) Paranoid parenting: Why ignoring the experts may be best for your child, London: Continuum.

Gillies, V. (2011) 'From function to competence: Engaging with the new politics of family', Sociological 
Research Online, 16(4)11. http://www.socresonline.org.uk/16/4/11.html

Gillies, V. (2013) 'From baby brain to conduct disorder: The new determinism in the classroom.' Paper given at the Gender and Education Association Conference, 25 April, London: London South Bank University.

https://www.academia.edu/3549456/From Baby Brain to Conduct Disorder The New Determinism in the Classroom

Goldson, B. and Jamieson, J. (2002) 'Youth crime, the 'parenting deficit' and State intervention', Youth Justice, 2: 82-99.

Hays, S. (1998) The Cultural Contradictions of Motherhood, New Haven and London: Yale University Press. Home Office (1998) 'Supporting Families: a consultation document', London: Stationery Office.

Illouz, E. (2007) Cold Intimacies: The Making of Emotional Capitalism, Cambridge: Polity Press.

Jensen, T. (2010) 'Warmth and wealth: re-imagining social class in taxonomies of good parenting', Studies in the Maternal, 2(1) 2010, www.mamsie.bbk.ac.uk

Kagan, J. (1998) 'The allure of infant determinism', pp.83-151 in Three Seductive Ideas (same author), Harvard Mass.: Harvard University Press.

Lawless, A., Coveney, J. and MacDougall, C. (2013) 'Infant mental health promotion and the discourse of risk', Sociology of Health and IIIness, 36(3): 416-431.

Lewis, J. (2011) 'Parenting programmes in England: Policy development and implementation issues, 2005-2010', Journal of Social Welfare and Family Law, 33(2), 107-21.

Lupton, D.A. (2011) “The best thing for the baby': Mothers' concepts and experiences related to promoting their infants' health and development', Health, Risk \& Society, 13(7/8), 637-651.

Nadesan, M. H. (2002) 'Engineering the entrepreneurial infant: Brain science, infant development toys, and governmentality', Cultural Studies, 16(3): 401-432.

Parton, N. (2006) Safeguarding childhood: early intervention and surveillance in a late modern society, Basingstoke: Palgrave Macmillan.

Ramaekers, S. and Suissa, J. (2012) The claims of parenting: Reasons, responsibility and society. Dordrecht, Heidelberg, London, New York: Springer.

Rose, N. (1999) Governing the soul: The shaping of the private self, London: Free Association Books.

Rose, N. (2010) 'Screen and intervene': governing risky brains', History of the Human Sciences, 23(1): 79105.

Rutter, M. (2002) 'Nature, nurture, and development: From evangelism through science toward policy and practice', Child Development, 73(1): 1-21.

Rutter, M. and the English and Romanian Adoptees (ERA) study team (1998) 'Developmental Catch-up, and Deficit, Following Adoption After Severe Early Global Privation', Journal of Child Psychology and Psychiatry, 39(4), 465-476. 
Smeyers, P. (2008) 'Child-rearing: On government intervention and the discourse of experts', Educational Philosophy and Theory, 40(6): 719-738.

Smeyers, P. (2010) 'State intervention and the technologization and regulation of parenting', Educational Theory, 60(3): 271-284.

Social Exclusion Unit (2004) 'Breaking the Cycle: Taking stock of progress and priorities for the future', London: Office of the Deputy Prime Minister.

Social Justice Policy Group (2007) 'Breakthrough Britain: Ending the costs of social breakdown, policy recommendations to the Conservative Party, London: Centre for Social Justice.

Sutton, C., Utting, D. and Farrington, D, (eds.) (2004) 'Support from the Start: Working with young children and their families to reduce the risks of crime and anti-social behaviour', Research Report 524 for the DfES.

Thornton Johnson, D. (2011) 'Neuroscience, affect and the entrepreneurialization of motherhood', Communication and Critical/Cultural Studies, 8(4): 399-424.

Vansieleghem, N. (2010) 'The residual parent to come: on the need for parental expertise and advice', Educational Theory, 6(3), 341-355.

Wall, G. (2004) 'Is your child's brain potential maximized? Mothering in an age of new brain research', Atlantis, 28(2): $41-50$.

Wall, G. (2010) 'Mothers' experiences with intensive parenting and brain development discourse', Women's Studies International Forum, 33(3): 253-263.

Wasoff, F. and Dey, I. (2000) Family policy, Oxon: Routledge.

Wastell, D. and White, S. (2012) 'Blinded by neuroscience: Social policy, the family and the infant brain', Families, Relationships and Societies, 1(3): 397-414.

Wilson, H. (2002) 'Brain science, early intervention and 'at risk' families: Implications for parents, professionals and social policy', Social Policy \& Society, 1(3): 191-202.

Wyness, M. (2013) 'Children, family and the State: Revisiting public and private realms', Sociology, 0(0): 1-16.

Dr Jan Macvarish is Research Fellow in the Centre for Health Services Studies at the University of Kent and one of the founding associates of the Centre for Parenting Culture Studies (CPCS) at the University of Kent. Her interests lie in the sociology of interpersonal relationships, parenting, family life, sex and intimacy, in particular, the interaction between policy, culture and lived experience. She has researched, taught and published on the subjects of contemporary singleness, teenage pregnancy, reproductive health, the regulation of fertility treatment and most recently, the impact of neuroscience on parenting culture. Recent publications include co-author of the book, 
'Parenting Culture Studies' (Palgrave Macmillan 2014) and the article “The First Three Years' Movement and the Infant Brain: A Review of Critiques', Sociology Compass, 8/6 (2014): 792-804. Address: Centre for Health Services Studies, University of Kent, Canterbury, Kent, CT2 7NF, England. email: j.macvarish@kent.ac.uk

Dr Ellie Lee is Reader in Social Policy at the University of Kent and Director of the Centre for Parenting Culture Studies (CPCS). She researches, publishes and teaches in the areas of the sociology of reproduction, of health, and of the family. Her longest standing research area is abortion policy and service provision. She has published works including Abortion Law and Politics Today (Macmillan 1998) and Abortion, Motherhood and Mental Health (Aldine Transaction 2003) and more recently she has worked on studies about the provision of 'late' abortion and early medical abortion. Since 2004 she has also developed research projects about motherhood (specifically feeding babies) and parenthood (the contemporary medicalisation of motherhood and fatherhood). Recent publications include co-author of the book, 'Parenting Culture Studies' (Palgrave Macmillan 2014), and the article, 'Assessing Child Welfare under the Human Fertilisation and Embryology Act 2008: A Case Study in Medicalization?, Sociology of Health \& IIIness, (2014) 36 (4).

Dr Pam Lowe is a senior lecturer in Sociology at Aston University. Her main research areas are centred around women's bodies and include reproductive health, domestic violence, sexual violence and exploitation. She is currently working on a number of research projects, including the construction of parenting cultures, pregnancy advice and the sexual exploitation. Recent publications include, 'Under the Influence: The construction of Foetal alcohol Syndrome in British Newspapers' Sociological Research Online (2010) 15 (4) 2 and 'Carers 2.0 ? New networked technologies and carers of people with dementia: interview study' (2010) Ageing and Society 30: 10731088. 